correspondingly larger protective immune response. This is the kind of effect that not only guarantees the persistence of H-2 polymorphism (though not necessarily its variety) but also may explain why the mouse, at least, goes to such lengths to increase $\mathrm{H}-2$ heterozygotes in the population above the 'natural' equilibrium frequency, by using recombination inhibition from the neighbouring $\mathrm{T}$ system in combination with a high frequency of lethal recessive alleles. Disassortative mating preference by external identification of $\mathrm{H}-2$ products or their effects will operate in the same direction.

Recognition of genetically endowed polymorphic pheromones may also play a part in maintaining the genetic integrity of incipient species in the face of a constant risk of interbreeding with the parent species. John Godfrey has shown for example, that subspecific variants of the bank vole Clethrionomys glareolus show a pheromone-dependent assortative mating preference for their own subspecies, given a choice. Some behavioural isolation is clearly a prerequisite for fixation of the subspecific gene complex: it would be interesting if the accumulation in a subspecies of polymorphic variants at genetic systems normally recognised as antigens were to play a part in this important phenomenon.

Clearly the Sloan-Kettering findings cannot be taken lightly. It is therefore a pity that the $\mathrm{H}-2$ associated mating preferences shown by the use of congenic lines were not confirmed in breeding tests, since trivial and unrecognised differences between lines, for example in housing, handling and maintenance could possibly have caused the effects that were seen. I hope that the work is soon confirmed and extended, and that the study of major histocompatibility polymorphisms has just begun a new life far from the inward mysteries of the immune response.

\section{Landslides in sensitive soils}

from I. J. Smalley

THE property of many sensitive clay soils in eastern Canada to transform suddenly and unexpectedly to material of virtually zero strength makes this region particularly prone to large landslides. Since the turn of the century, landslides in eastern Canada have cost more than 100 lives and involved the loss of more than 20,000 acres of upland. Another large landslide may threaten this spring on the calculation that these massive earthflows occur on average every four or five years and the last one, in which 31 people were killed, occurred at St Jean Vianney in 1971. 'Sensitive' soils have a very high ratio of undisturbed strength to remoulded strength but the nature of the transition and the factors which control it are not yet established despite the investigations which have followed in the wake of the St Jean Vianney disaster.

The Terrain Sciences Division of the Geological Survey of Canada has carried out extensive mapping in sensitive soil regions, and the geological setting of the problem in eastern Canada is becoming clearer (Gadd, Proc. 4th Guelph Geomorphology Symp. 137; 1975). Extensive studies of the pore water chemistry (Torrance Can. Geotech. J. 12, 326; 1975) suggest that the leaching effect first described by I. T. Rosenquist in the late 1940s should still be considered a significant factor in Canadian clays, although there appears to be no direct correlation between leaching and sensitivity. Another interesting lack of correlation is that between sensitivity and size of landslide; a conclusion reached by Mitchell and Markell after a study of 75 landslides (Can. Geotech. J. 11, 11; 1974).

Interparticle cementation, by producing strong but brittle bonds, could be an important factor contributing to sensitivity. Attention has been focused recently by $R$. N. Yong and his collaborators at McGill University on the presence and importance of amorphous matter as a cementing agent in these clays and it seems that some soils may have an amorphous matter content as high as $40 \%$. Mineralogical studies on sensitive soils still present problems, mainly those of making quantitative estimates of constituents. Some initial thermogravimetric studies have been made on clay from the St Jean Vianney slide and further studies are in progress on material from the vicinity of another large 1971 event-that at South Nation River. The lack of clay minerals is notable; Gillott (Can. Mineral. 10, 797 ; 1971) was one of the first to draw attention to the predominance of primary mineral particles (as distinct from clay mineral particles) in the Canadian sensitive soils. The soils, as a result, have a very low plasticity index and the low plasticity facilitates the solid-liquid transition. Cementation provides extra strength but once the interparticle bonds are broken there are insufficient clay minerals to influence the abrupt change in strength properties.

Mitchell and Klugman (Engng Geol. in the press) in a survey of recent Canadian work report that regional differences in sensitive soils are becoming more apparent although the occurrence of landslides of the characteristic form may be more widespread than has been realised. Critical factors may be revealed when the scope of investigations can be enlarged to include the less accessible regions, in particular Labrador. An improved classification of sensitive soils is also required and R. Söderblom at the Swedish Geotechnical Institute has recently taken a significant step in this direction (SGI Prelim. Rept 55, 1974). He is concerned with soils of extreme sensitivity (often called quickclays, after the Swedish term kvicklera) and has distinguished two distinct types. Those which require a considerable energy input to cause the solid-liquid transition he calls 'slow quick clays' and those which transform easily are 'rapid quick clays'. The new parameter of rapidity can be assessed using a standard Casagrande liquid limit device, and should prove very useful when sensitive soil comparisons are being made.

\section{Relapses in malaria}

\section{from F. E. G. Cox}

RELAPSES, months or even years after an initial infection, are characteristic of malaria and in the quartan disease an individual may experience periodic fevers for the whole of his life. Until the discovery of the exoerythrocytic stages of malaria in the liver in 1948 it was widely assumed that during the remissions the parasites persisted in the blood at subpatant levels and that their spasmodic appearances in larger numbers represented recrudescences rather than true relapses. Relapses proper only occur when the blood is quite free from parasites during the intervals between periods of patency. The discovery of exocrythrocytic stages in the liver immediately suggested that it was there that they sojourned and from time to time flooded the blood with new erythrocytic forms. A number of observations, however, have indicated that this explanation is too simple (Garnham Protozool. Abstr. 1, 1; 1977) and recent work in the Soviet Union and Romania suggests an alternative hypothesis.

It has been suspected for some time that the tertian malaria parasite, Plasmodium vivax, exists in two forms, one with a short prepatent period (13-16 d) before parasites appear in the blood following infection from a mosquito and the other with a less clearly defined longer period of $300 \mathrm{~d}$ or more (Sergiev \& Tiburskaya Arch. Roumaines Path. exp. Microbiol. 26, $475 ; 1967)$. The short prepatent form is characteristic of tropical strains and the other is typically found in more temperate regions such as the Soviet Union and North Korea. Using a North Korean strain a team of nine cowork- 